\title{
Introductory remarks*
}

\author{
DONALD I. TEPAS $†$ \\ Saint Louis University, Saint Louis, Missouri 63103
}

The first commercially marketed computer became available about 20 years ago. In the face of an inflationary economy, astonishing advances in technology have resulted in faster and more powerful computers, decreased data processing costs, reductions in processor size, and an exponential growth in the number of computer programmers (Bowden, 1970). It appears that four generations of computers will have been developed in the time span of less than one human generation. The Chevrolet-priced (less than $\$ 4,000$ ) computer is now a reality and can be bought off-the-shelf. The Honda-priced (less than $\$ 1,000$ ) remote computer terminal is similarly available. A central processor the size of a desk drawer is not astonishing to the present-day computer consumer, but rather an expected standard feature of the minicomputer. In short, on-line computer facilities are becoming economically feasible for more and more scientists at a truly impressive rate.

Computer time-sharing is becoming more and more a reality as the capacity and availability of computers soars to new heights. Large-capacity data storage is no longer a dream. $\mathbb{A}$ company is now building a random access computer memory system with a storage capacity of two trillion bits of information. Random access to any one of the two trillion bits is expected to take an estimated average of only 10 sec. University computer centers that handle thousands of jobs per day are in operation. Recent Federal Communications Commission approval for the construction of nationwide microwave networks specifically designed for the transmission of digital computerized data will result in the

*This conference was supported by Grant GJ.30857 from the Office of Computing Activities of the National Seience Foundation. As Principal Investigator of the grant. I wish especially to thank NSF and Saint Louis University for the special efforts made to keep the conference on schedule and adequately serviced. In addition, the assistance of Roger L. Klingaman, Frederick A. Mote, The Psychonomic Society, Joseph B. Sidowski, and the conference exhibitors is sincerely acknowledged.

tAddress: Department of Psychology, Saint Louis University, 221 N. Grand Boulevard, St. Louis, Missouri 63103. transmission of data at rates $\mathbf{1 0}$ times faster than those of the Bell system at lower no-minimum-time rates in the very near future. Clearly, low-cost minicomputers and time-sharing computer terminals are developing at such a rate that they will become academic and economic necessities in the very near future. On-line computer approaches are already suggesting that the batch-oriented central university computer center may no longer be practical (Michaels, 1970).

Since data collected by psychologists frequently requires extensive statistical analysis, campus computer centers have been frequented by psychologists for many years. What is perhaps less widely recognized is the pioneering role which many psychologists played in the early use of time-sharing and real-time computer applications. As the coauthor of a research paper using an on-line computer system which was published over 10 years ago (Armington, Tepas, Kropfl, \& Hengst, 1960), many scientists might rate me as a pioneer in this new and expanding area. I am confident, however, that many psychologists attending this conference can date their use of on-line computer systems to an earlier date. The LINC computer, developed under grants from the National Institutes of Health in the early $1960 \mathrm{~s}$, is probably the most widely known precursor of the third-generation minicomputer explosion. Early use of this laboratory-based system by psychologists and neurophysiologists in a productive manner led to applications in physics, chemistry, oceanography, and other areas. The pioneering book of Bert F. Green (1963) provides a good example of the leadership which psychologists have demonstrated.

Given the assumption that many psychologists are and will be significantly involved in the expanding use of on-line computer systems, it appears reasonable to suggest that psychologists should have a forum wherein they can discuss openly all aspects of on-line computer applications. Unfortunately, there is little in the way of hard factual information to support the contention that many psychologists are interested in such an activity. Fortunately, the
National Science Foundation saw fit to support this conference. Despite the fact that just over 2 months' time was available to announce, schedule, and organize this conference, over 270 psychologists registered for these sessions. In addition, 11 psychologists accepted invitations to present prescribed papers and 19 psychologists volunteered to make workshop presentations. This enthusiastic response with such short notice should clearly indicate that the scope and extent of psychologists' use of on-line computer systems continues to expand and develop.

In the organization of this conference, a number of assumptions were made. It was assumed that psychologists would do the best job of communication with a gathering of psychologists. Thus, only psychologists were invited to make presentations. Areas of inquiry within psychology are so diverse that it can be assumed that there is a similar diversity of techniques and systems for information processing. Therefore, psychologists from a variety of specialties were invited to participate. In addition, participants were invited so as to allow attendees to hear reports on systems produced by a variety of manufacturers. Finally, invited speakers were asked to direct their presentations towards both current and potential on-line computer system users. I assumed that the objectives of the conference should not be limited to the needs of those already using on-line systems. Obviously, potential computer users can greatly benefit from the advice, guidance, and experiences of current users. An initial examination of those attending this conference supports many of these assumptions. Of those attending the conference, $32 \%$ have no current access to a computer system of any sort. Of those attending the conference who have a computer access, $89 \%$ have access to an on-line computer system. Over a dozen different manufacturers were involved in the on-line computer systems used by those attending.

Thus, the conference consists of a gathering of psychologists, with varying degrees of sophistication in on-line computer applications, interested in a variety of applications 
and using systems of differing manufacture. As a first effort, such a hybrid composition would appear both desirable and necessary. When we complete the conference, however, we must ask some important questions concerning possible future activities of this sort. Should future conferences be considered? Is a more formal or specialized organizational structure needed? If additional conferences are needed, to whom should they be directed, and at what level? I do not think we should ignore these methodological questions, and I invite your suggestions.

Psychologists who use on-line computers in many ways have a special obligation to their colleagues inside and outside of psychology, which should not be ignored. While the cost of computer use has decreased in recent years, the expenditures of higher education for computing services have increased sixfold in the last 6 years (Mosmann \& Stefferud, 1971). The cost of computer use will continue to decrease. Continued reductions in the price of new systems, the increasing availability of used computer systems, the expected availability of government surplus equipment, and software advances should insure this. Current university and grant-agency economics will not, however, promote increased spending to accommodate the more widespread use of on-line computer systems. We do have an obligation to our colleagues, naive and sophisticated, to generate methods whereby efficient and appropriate applications of on-line computer systems are assured. In the past, we have been mainly dependent upon the manufacturers for applications information and advice. As many of us will testify, there is little to assure that these traditional sources need be either satisfactory or reliable. We must consider the development of methods of information exchange which are independent of the manufacturers or of chance personal acquaintances. Equally important, perhaps, is the need to develop software and hardware standards and methods tailored to on-line computer applications in psychology but independent of specific manufacturer or experimenter idiosyncrasies.

Many of the problems and obligations mentioned above suggest a need to improve communication and educational opportunities for ourselves and our colleagues. We must not forget our obligations to other members of the scholarly world. In general, administrators and undergraduates share a common problem: little direct contact with computers and computer applications (Scully, 1971). If on-line computer systems are to enjoy even wider popularity in the future, we must consider the possibility that on-line computer applications in psychology are so specialized and specialty-dependent that the appropriate education and training may not be provided by specialists from other disciplines. Just as we cannot depend upon manufacturers for information and training, we also cannot depend upon other disciplines to assume these duties.

In summary, I hope that this conference will be noted not only as a first gathering of psychologists who use on-line computers, but also as the start of an attempt to organize efforts towards improving the overall dissemination of information concerning on-line computer applications in psychology. We must consider new and better ways of assuring and expanding the appropriate use of computers in our discipline.

\section{REFERENCES}

ARMINGTON, J. C., TEPAS, D. I. KROPFL, W. J., \& HENGST, W. H. Horne and M. A. Whitcomb (Eds.), Vision research reports. Washington, D.C: National Academy of Sciences-National Research Council, 1960.

BOWDEN, L. The language of computers. American Scientist, 1970, 58, 43-53.

GREEN, B. F. Disital computers in research. New York: McGraw-Hill, 1963.

MICHAELS, P. Remote terminals replace university computer center. Electronic Systems Engineering, May/June 1970.

MOSMANN, C.. \& STEFFERUD, E. Campus computing management. Datamation, March 1971, 20-23.

SCULLY, M. G. Computers, big in research, little-used by undergraduates. The Chronicle of Higher Education, October 12, $1971,4-5$.

\title{
Various uses of minicomputers in psychology
}

\author{
JOSEPH B. SIDOWSKI \\ University of South Florida, Tampa, Florida 33620
}

I am not at all certain that the title of this presentation adequately describes what I have to say, for there are various ways to look at the "Various uses of minicomputers in psychology." A better title might have been "Who else uses these computers, so you'll know whom to contact when the lights go out" or "The various means available to psychologists for obtaining information provided by other computer users from all sorts of areas and installations to help them make the damn things work in the laboratory." Whatever, it is difficult to improve on the computer-use descriptions provided by Uttal's volume on real-time computers (1968) and those of many others who for years have attempted to educate us concerning the ways in which small computing machines might be used both on-line and in a real-time process-control sense. The forthcoming volume edited by Bernie Weiss (Digital computers in the behavioral laboratory) will update the attempt (1972). So, in the time available, I will attempt to skip through varied bits of information concerning minicomputer uses and hope, in the process, to communicate a little of something to each of you in this diversified audience.

Before going on, however, I would like to define minicomputer and will do so in spite of some disagreement within the industry concerning an exact definition. Generally, the machines are considered smaller versions of the large scale, general-purpose computers, organized in somewhat the same manner internally, allowing for similar programming techniques and for the same types of peripherals. A mini includes a central processor with general-purpose registers, core, and a set of instructions, and accepts and stores a program that the user can alter. The memory most often has a minimum of 4,096 words, with word lengths varying from 8 to 24 bits, depending on the machine and the application. The user can input commands to the system, and he receives results and instructions from it. Finally, it is small in size and costs no more than $\$ 25,000-\$ 30,000$ for the basic unit; the cost at the lower end of the scale can be less than $\$ 3,000$ (Sidowski, 1970). Beyond the above requirements, modern minis may have all sorts of features which increase capabilities and costs tremendously. For many process-control situations found in the laboratory, an off-the-shelf basic minicomputer costs little more than a specially designed logic module controller. But there is little justification for using it where a cheap hard-wired controller can do the job.

Obviously, in order to test 